\title{
Preservation, transportation and constraints of hide and skin in Woliso woreda, South West Shoa Zone, Oromia region Ethiopia
}

\begin{abstract}
The current study was conducted in Woliso Woreda, South West Shoa Zone, Oromia regional state, Ethiopia with the objective of assessing hide and skin preservation and transportation system and constraints. For the present study, 5 kebeles were selected purposively based on their potential of hiding and skin preservation. Then 15 respondents were selected from each kebeles purposively based on the experience and involvement of hiding and skin preservation. Thus, totally 75 households were included in the study. The data was collected using both primary and secondary sources. The collected data were analyzed by using descriptive statistics and the result was presented and described by using per cent and figure. The majority of the respondents (73.3) practice wet salting method to preserve hide and skin. However, only $26.7 \%$ of the respondents practice dry salting. The majority of the respondents $(49.3 \%)$ collect hide and skin at slaughter time whereas 36 and $14.7 \%$ of the respondents collect hide and skin after a while and next day respectively. The result of the present study indicated that the main constraints of marketing of the study area are lack competitive market $(53.4 \%)$, fluctuating price $(13.3 \%)$ and lack of price information $(33.3 \%)$ Therefore, based on the present study, pieces of training on handling, storage and preservation methods needed to increase the quality of trader the farmers, middlemen and collectors should take.
\end{abstract}

Keywords: hide, skin, salting, preservation, slaughter
Volume 3 Issue 3 - 2018

\author{
Gezu Etissa,' Abera Anja² \\ 'Woliso Woreda, Office of Agriculture, Ethiopia \\ ${ }^{2}$ Department of Animal and Range sciences, Wolaita Sodo \\ University, Ethiopia
}

\begin{abstract}
Correspondence: Abera Anja, Department of Animal and Range sciences, Wolaita Sodo University, College of Agriculture, Ethiopia, Tel 2519-1362-8416,
\end{abstract}

Email anjabisrat@yahoo.com

Received: May 24, 2018 | Published: June 05, 2018

\section{Introduction}

Ethiopia is relatively well endowed with its livestock with estimated of 56.71 million cattle, 29.33 million sheep and 29.11 million goats. ${ }^{1}$ This livestock population contributes in many ways to house hold incomes and food security, as drought animals and through milk production; they are sold or slaughtered, at an advanced age, or in case of urgency. The availability of hiding and skins through slaughtering or death of livestock is a particular importance to the leather industry. Hide and skin is mainly obtained from cattle, sheep and goats. Based on annual of taking rates of $71.12 \%$ for cattle, $31.11 \%$ for sheep, and $35.37 \%$ for goats, the potential production is estimated at 3.7 million cattle hides, 8.7 million sheepskins and 8.1 million goat's skins. Hides are broadly defined as external integument of large animals, while skins are provided by small animals. The best source of hiding and skin animals domesticated animals are cattle for hides and sheep and goat for the skin. However hide and skin may also be obtained from other species of domesticated and non-domesticated animals (hide from Buffalo, camels etc. and skin from (rabbit, pig etc.). ${ }^{2}$ The hide and skin is a product of animal production as end product also more correctly they are by-product. Abadi ${ }^{3}$ illustrated that Ethiopian small ruminant skins, especially sheep skins traditionally have a very good reputation for quality in the world leather market due to their fine grain and compact structure. Generally, the defect of hiding and skins, during pre-slaughter operations has a direct contribution in reducing income from hiding and skin production. Proper collection and processing determine the extent of loss from hiding and skin. Those hides and skins which is not collected and processed properly are discarded. Then due to improper slaughtering, this happens but the majority of losses occur because of damages to these products before and during collection. ${ }^{4}$ The main problems mentioned above are related to the low quality of hide and skin due to lack of better grading during the selection of rawhide and skin while the hide and skin are purchased. These again related to the inadequate number of abattoirs and slaughter slabs, a distance between market and potential supplies. Even though- Woliso Woreda is known to be potential in livestock production; the products like hiding and skin preservation system and marketing are not yet studied and documented. Therefore, this study is aimed to assess hide and skin preservation and constraints system in Woliso Woreda which enables to enhance the products by identifying the gaps in the preservation of hiding and skin.

\section{Materials and methods}

\section{Description of the study area}

The study area was conducted in Woliso Woreda, South West Shoa Zone, Oromia regional state. Woliso Woreda-has located $114 \mathrm{~km}$ from Addis Ababa which is the capital city of Ethiopia. It is found to South West at the latitude of $8^{\circ} 32^{\prime}$ 'North and $37^{\circ} 58^{\prime}$ ' East longitude and elevation of $2063 \mathrm{~m}$. a. s. 1. The area is characterized by dry sub-humid climate with annual rainfall $1200 \mathrm{ml}$ and temperature of $18-27^{\circ} \mathrm{C}$. The total human population of the study area has an estimate of 37,878 from which 18,880 and 18,998 are men and women respectively. Woliso Woreda has livestock population of 1,666,008, 20,931 and 30,631 cattle sheep and goats respectively. ${ }^{5}$ 


\section{Sampling techniques}

Woliso Woreda has 18 Kebeles which are midland agro-ecology. For the present study 5 kebeles (Abedo Lemen, 01, 03, Bedesa Koricha and 02 ) were selected purposively based on the potential of hiding and skin production for the study. Then 15 respondents were selected from each kebeles purposively based on the experience and of hiding and skin preservation. Thus the total number of households selected for the present study was 75 (i.e. 5 kebeles* 15 respondents).

\section{Data collection methods}

The data was collected from both primary and secondary sources. The primary source of data was collected by preparing semistructured questionnaires to the respondents. The secondary data was collected from varies sources including public organization, documented materials, from either governmental or nongovernmental organizations.

\section{Methods of data analysis}

The data were analyzed by using descriptive statistics and was presented in the form of a percent and the results were described by using table and figure.

\section{Results and discussion}

\section{Socio-economic characteristics of the respondents}

\section{Age and sex of the respondents}

As indicated in Table 1, in the study area the majority $(86.7 \%)$ of respondents' age is found in the range between 17 and 65 years and there are no respondents below 16 years of age. According to the present findings, the majorities of respondents are within productive age group and can participate effectively in the activity of hiding and skin production and preservation. However, only about $13.3 \%$ of the respondents are found above 66 years of age. As indicated in Figure 3 , the majorities $(80 \%)$ of respondents are male and the remaining $(20 \%)$ of respondents are female. From this result, it can be concluded that male had more responsibility for all activity of hiding and skin whereas females had less responsibility (Figure 1). According to the survey result, the majority ( $88 \%$ ) of respondents were educated at the different level from elementary to above secondary school whereas only about $12 \%$ of the respondents were illiterate (Table 2). It is known that education has a great role in determining the society to accept new technology. Accordingly, the higher proportions about $33.3 \%$ of the respondents were educated primary school. As indicated in Table 3 , the majority of the respondents $(53.3 \%)$ were married. However, about 20,7 and $7 \%$ of the respondents were single, widowed and divorced respectively.

\section{Preservation of hide and skin}

According to Table 4, the sampled respondents in the study area practice two types of preservation methods which are wet salting and air drying. The majority of the respondents (73.3) practice wet salting method to preserve hide and skin. However, only $26.7 \%$ of the respondents practice dry salting. Similarly, Ahmed ${ }^{6}$ stated that hide and skin ready for the market should be preserved either by air drying or wet salting in areas where the tanner is close to the source the raw material. This finding disagrees the finding of ${ }^{7}$ who indicated that about $94.01 \%$ of the respondents used the preservation methods of ground air dry while about $6.25 \%$ use salt preservation for hiding and skin preservation. As it is indicated in Figure 2, the higher proportion $(53.3 \%)$ of the respondents sold some and kept the preserved hide and skin for home use whereas, 26.7 and $20 \%$ of the respondents kept for home use and sold all respectively. In this regard, the respondents use to hide and skin for different purposes like preparing bedding materials.

Table I Age of the respondent's

\begin{tabular}{lll}
\hline Age of the respondent's & $\begin{array}{l}\text { Number of the } \\
\text { respondent's (N=75) }\end{array}$ & Percent \\
\hline Lower than 17 & 0 & 0 \\
$17-65$ & 65 & 86.7 \\
$>66$ & 10 & 13.3 \\
\hline
\end{tabular}

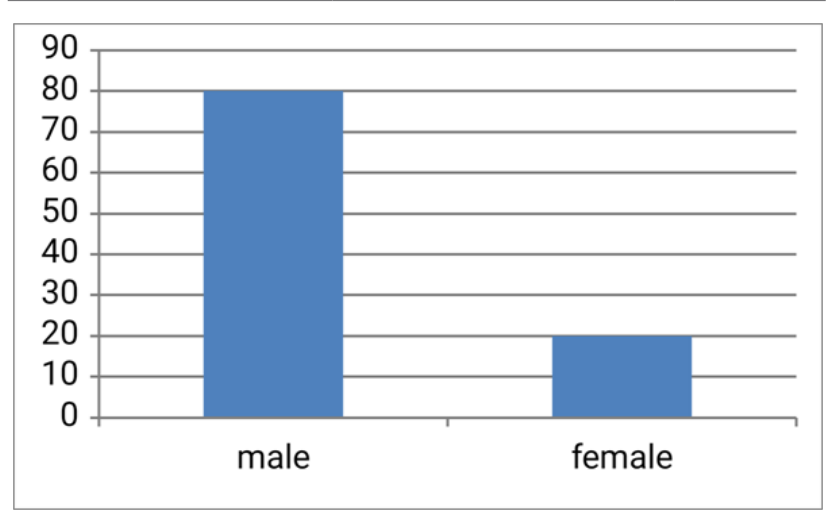

Figure I Sex of respondents.

Table 2 Level of education of respondents

\begin{tabular}{lll}
\hline Educational level & $\begin{array}{l}\text { Number of the } \\
\text { respondents }(\mathbf{N}=\mathbf{7 5})\end{array}$ & Percentage (\%) \\
\hline Illiterate & 9 & 12 \\
Read only & 15 & 20 \\
Elementary & 25 & 33.3 \\
Junior & 11 & 14.7 \\
Secondary & 7 & 9.3 \\
Above secondary & 8 & 10.7
\end{tabular}

Table 3 Marital status of respondents

\begin{tabular}{lll}
\hline Marital status & $\begin{array}{l}\text { Number of the } \\
\text { respondents }(\mathbf{N}=\mathbf{7 5})\end{array}$ & Percentage (\%) \\
\hline Single & 20 & 26.7 \\
Divorced & 6 & 8 \\
Married & 45 & 60 \\
Widowed & 4 & 5.3 \\
\hline
\end{tabular}


Table 4 Preservation method of hiding and skin

\begin{tabular}{lll}
\hline Method of preservation & $\begin{array}{l}\text { Number of } \\
\text { respondents(N=75) }\end{array}$ & Percentage (\%) \\
\hline Air drying & 20 & 26.7 \\
Wet salting & 55 & 73.3 \\
\hline
\end{tabular}

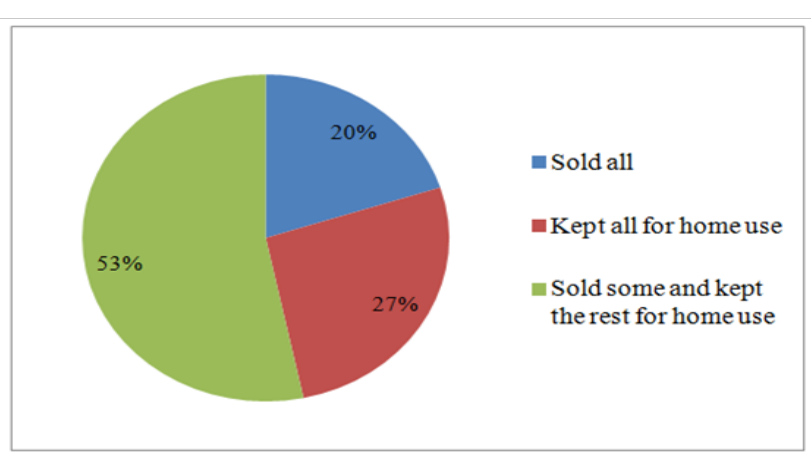

Figure 2 Uses of preserved hide and skin.

\section{Collection of hide and skin}

As it is indicated in Table 5, respondents indicated that collectors collect hide and skin in different time. The higher proportion of the respondents $(49.3 \%)$ collect hide and skin at slaughter time whereas 36 and $14.7 \%$ of the respondents collect after a while and next day respectively. From the present findings, the collection of hiding and skin collected immediately after slaughter by the higher portion of the sampled respondents is very important to reduce post-harvest spoilage of hiding and skin. However, much attention should be given to the respondents to collect hide and skin at slaughter time for respected hide and skin collection centre to maximize profit by keeping quality hide and skin.

Table 5 Collection of hiding and skin

\begin{tabular}{lll}
\hline Time of collection & $\begin{array}{l}\text { Number of the } \\
\text { respondents }(\mathbf{N}=\mathbf{7 5})\end{array}$ & Percent \\
\hline At slaughter time & 37 & 49.4 \\
After a while & 27 & 36 \\
Next day & 11 & 14.6 \\
\hline
\end{tabular}

\section{Quality of hide and skin}

According to the present survey result, several reasons may contribute to low quality of hiding and skin. As it is indicated in Table 6 , about $30.7,26.6,22.7$ and $20 \%$ of the respondents argued that the low quality of hiding and skin was due to inappropriate slaughtering, flaying, collection and poor animal husbandry respectively. Hide and skin defects assessments were made through visual inspection at collection centers during the study in the study area. Similarly, CSA (2004) reported poor pattern dirt and knife cut as the main defect of sheep and goat. From the present findings, it can be concluded that much work should be done with respected stakeholders like governmental and non-governmental agents to keep the quality of hiding and skin.

\section{The transportation system of hide and skin}

As indicated in Table 7, there are different methods of transporting hide and skin to the market in the study area. Accordingly, the higher proportion $(40 \%)$ of the respondents used animal transport method to transport hide and skin to the village market, Woreda market, middlemen or to local processors. However, about 33.3, 20 and 6.7\% of the respondents used a cart, vehicle and on foot respectively as transportation means of hiding and skin to market depending on the economic condition of the respondents (Figure 3).

Table 6 Factors contribute to low quality

\begin{tabular}{lll}
\hline Parameter & $\begin{array}{l}\text { Number of the } \\
\text { respondents }(\mathbf{N}=\mathbf{7 5})\end{array}$ & Percentage (\%) \\
\hline Poor animal husbandry & 15 & 20 \\
Inappropriate slaughtering & 23 & 30.7 \\
Flaying & 20 & 26.6 \\
Collection & 17 & 22.7 \\
\hline
\end{tabular}

Table 7 Constraints of hiding and skin marketing

\begin{tabular}{lll}
\hline Production problem & $\begin{array}{l}\text { Number of the } \\
\text { respondents }(\mathbf{N}=\mathbf{7 5})\end{array}$ & $\begin{array}{l}\text { Percentage } \\
(\%)\end{array}$ \\
\hline Disease & 36 & 48 \\
Flay defects & 24 & 32 \\
Injury & 15 & 20 \\
\hline Market problem & & \\
\hline Lack of competitive market & 40 & 53.4 \\
Fluctuating price & 10 & 13.3 \\
Lack of price information & 25 & 33.3 \\
\hline
\end{tabular}

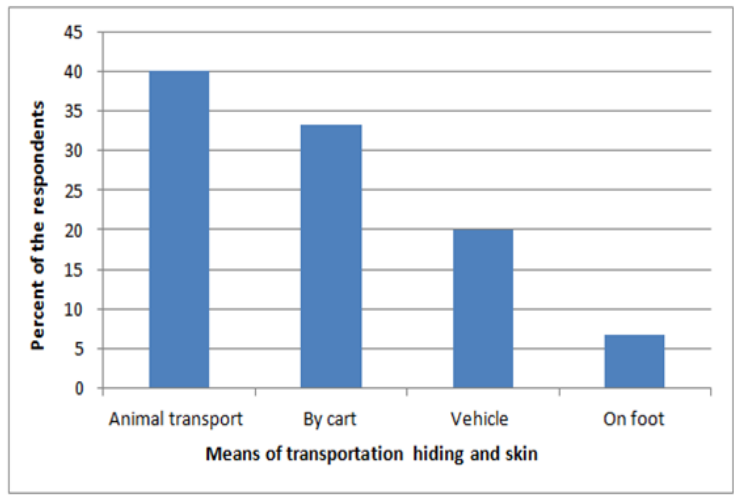

Figure 3 Transportation systems of hiding and skin.

\section{Constraints of hide and skin marketing}

According to Table 6, hide and skin is affected by pre-slaughter defect accumulated during the life of animal, pre-slaughter defect, during handling. According to the information collected from the respondents about $48 \%$ of the respondents argued that the main constraints of hiding and skin were defeated by disease whereas 32 and $20 \%$ of the respondents indicated that the defects were due to flay effect and injury respectively. The result of the present study indicated that the main constraints of marketing of hiding and skin were lack of competitive market (53.4\%), fluctuating price (13.3\%) and lack of price information $(33.3 \%)$. The other quality deterioration of hiding and skin in the study area related to wrong handling practices. The wrong handling result downgrading of hiding and skin during collection. 


\section{Conclusion and recommendations}

The current study was conducted in Woliso Woreda, South West Shoa Zone, and Oromia regional state, Ethiopia to assess the potential of hide and skin preservation and constraints. For the present study 5 kebeles namely Abedo Lemen, 01, 03 , Bedesa Koricha and 02 were selected purposively based on their potential of hide and skin. Then 15 respondents were selected from each kebeles purposively based on the experience and potentials of hide and skin preservation. Thus the total household selected for the present study was 75 . The data was collected using both primary and secondary sources. The primary source of data was collected by preparing semi-structure questionnaires. In the study area the majority $(86.7 \%)$ of respondents' age is found in the range between 17-65 years and there are no respondents below 16 years of age. The majority $(80 \%)$ of respondents were educated at different level from elementary to above secondary school whereas $26.7 \%$ of the respondents were illiterate. The respondents of the study area practice two types of preservation methods which are wet salting and air drying. The majority of the respondents $(73.3 \%)$ practice wet salting method to preserve hide and skin. However, only $26.7 \%$ of the respondents practice dry salting. There are different methods of transporting hide and skin to market. Higher proportion (40\%) of the respondents used animal transport method to transport hide and skin to market. The major constraints of hide and skin includes pre-slaughter defect which are accumulated during the life of animal and market.

According to the result of the present study the following recommendation were made:

1. So to increase the quality of trader the farmers, middlemen and collectors should take trainings on handling, storage and preservation methods

2. Much work should be done with respected stakeholders like governmental and non-governmental agents to keep the quality of hide and skin.

\section{Acknowledgements}

None.

\section{Conflict of interest}

The author declares there is no conflict of interest.

\section{References}

1. Central Statistics Authority (CSA). The Federal Republic of Ethiopia Agricultural Sample Survey. Report on Livestock and Livestock Characteristics. Statist. Bull. 2015;578(II):23.

2. FAO. Food and agricultural organization world statistically compendium or rawhide and skin, leather and leather product for the years 1982-2004. Rome, Italy; 2004.

3. Abadi Y. Current problem of leather industry. In: Merkel RC, Abebe G, Goetsch AL, editors. Debub University, Awassa, Ethiopia, 2000;139-143.

4. FAO. Food and agricultural organization higher value addition through hide and skin. Rome, Italy; 2009.

5. ARDWW (Agriculture and rural development of Woliso Woreda). Woliso Woreda, South West Shoa Zone, Oromia regional state, Ethiopia; 2010.

6. Ahmed Mohamed. Rawhide and skin improvement in Ethiopia (status and Challenges) a paper presented on technical works shop on good Practice for Ethiopia hide and skin in Addis Ababa, Ethiopia; 2001.

7. Getachew Bekele Fereja, Merhun Lamaro, Genet Berhe, et al. Study on production potential and preservation methods of Hide and skin in three selected districts of Gambella region, south-west Ethiopia. International Journal of Research Granthaalayah. 2017;5(2):142-150. 